\title{
Planetary mobilities: movement, memory and emergence in the body of the Earth
}

\section{Bronislaw Szerszynski, Lancaster University}

author final version, July 2016 -

to appear in the journal Mobilities

\begin{abstract}
In this paper I present a unified framework for understanding abiotic, biotic and technological mobilities as achievements of a far-from-equilibrium planet self-organising over geological time, and generating informationally rich forms of matter and motion. I discuss how flows of energy through the Earth support the emergence of different kinds of movement in spatially distinct 'mobility regions' and scale-related 'mobility situations'. I also discuss how technological mobilities exhibit forms of 'gratuity', a relative uncoupling of different aspects of motion, which have arisen repeatedly in the Earth's past, and may presage the emergence of radically new forms of planetary mobility.
\end{abstract}

KEYWORDS: mobilities, complexity, self-organisation, Earth systems, physics, thermodynamics, mobility regions, mobility situations, gratuity

\section{Contents}

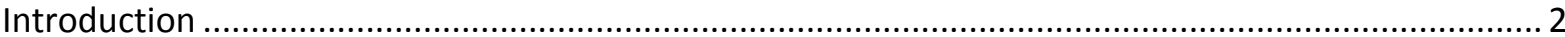

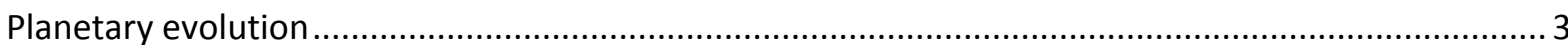

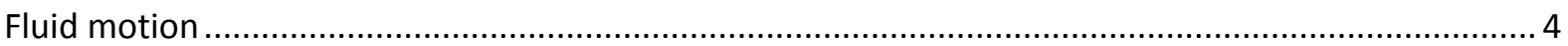

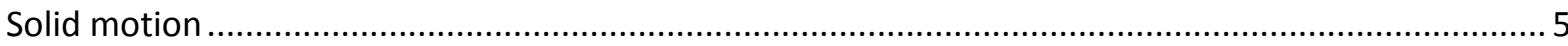

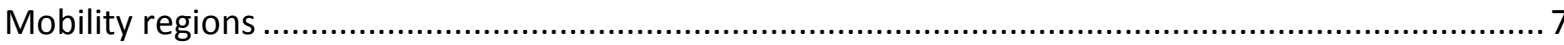

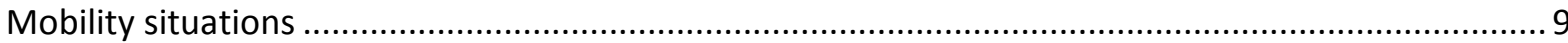

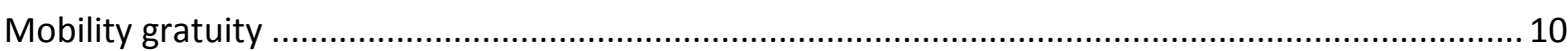

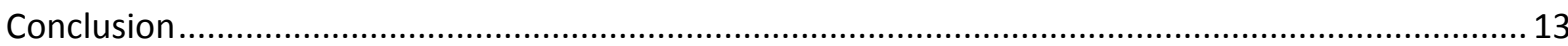

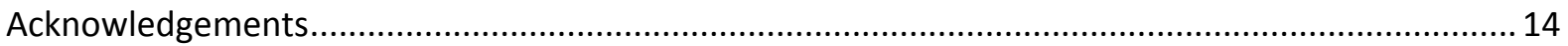

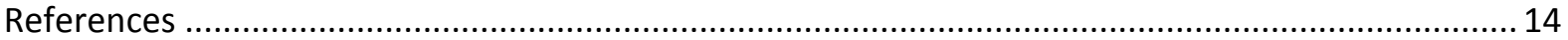




\section{Introduction}

The now well-established interdisciplinary field of mobilities - the study of large-scale movements of people, objects and information across the world - has its roots in the social sciences, yet often draws some of its vocabulary from the physical sciences. For example, authors have described mobilities in terms of flow (Law, 2006; Urry, 2003, pp. 59-74), turbulence (Cresswell and Martin, 2012), friction (Cresswell, 2013; Tsing, 2005) and viscosity (Doherty, 2015). However, these concepts have largely been deployed in a metaphorical way, and there has been little sustained engagement in the mobilities field with the physical sciences. In this paper I will make a contribution to correcting this lacuna, showing how insights from a number of scientific fields including fluid dynamics, thermodynamics, animal locomotion, geomorphology and astronomy, can be combined to shed light on the movement of people and things.

In particular, building on the work of Peter K. Haff (2010; 2012), I will set out an approach to mobilities that makes no a priori distinctions between the abiotic (non-living, physico-chemical processes), the biotic (organic life) and the technological (artefacts, tools and machines), and that treats all mobilities in the Earth as emergent phenomena generated by a planet organising itself under the constraints of physical laws and imperatives. Thus, by talking about planetary mobilities I am not simply referring to long-distance mobilities, or mobilities that accumulate into a dense set of connections over the surface of the Earth; treating the Earth as a loosely-bounded dynamic assemblage that extends through the atmosphere into near space, I am suggesting that we should look at all mobilities occurring in the Earth as achievements of a far-from-equilibrium planet, under the thermodynamic imperative to dissipate energy gradients, self-organising over deep, geological time and thereby creating its own unique history and set of powers. In order to do so we will have to talk not just about motion - of both fluids and solids - but also information, here defined as rare and highly correlated states of matter that are difficult to achieve (Hidalgo, 2015), and various forms of 'Earth memory', in which information is not just created but also preserved and made available in the future to enable the planet to do new things.

Since for a large part of the paper I will be suspending distinctions between the abiotic, the biotic and the technological with a view to highlighting wider patterns that cut across them, I will use some broad, cross-cutting categories of mobility. An important distinction made by Haff (2010) is that between advective movement (mass parallel motion) and diffusion-like movement (multidirectional movement with frequent changes of direction), but other distinctions that I will use will include those between mixing (destroying density gradients) and sorting (creating density gradients), singular versus repeated motions (the latter including both the 'shuttling' of specific entities and 'cycles' involving classes of entity or materials) and random and directed motion. In practice, none of these mobilities is likely to happen in isolation. On the contrary, a further characteristic of mobilities in a dense, relatively enclosed and self-organising part of the universe like the Earth is that mobilities spatio-temporally 'tune' or 'clash' with each other (Haff, 2010, p. 1164).

Three concepts will emerge as particularly important in my analysis of planetary mobility. I will discuss various 'mobility regions' - spatially distinct zones with different material and energetic characteristics - and 'mobility situations' - particular balancings of forces at different scales and speeds. In all of these, physical properties combine to make possible particular kinds and powers of mobility. But I will also suggest that some kinds of mobility exhibit forms of 'gratuity', a relative uncoupling of different dimensions of mobility such as those of power and direction, carrier and carried, or matter and information. While gratuity is more clearly manifest in anthropogenic, technologically mediated forms of mobility, it also points to a wider dynamic in planetary mobilities and can help guide speculation about possible planetary futures. But in the next section I will first start to explore how we can understand the complex, interlinked set of mobilities in the Earth as a planetary phenomenon - as radically conditioned by the long, emergent process of the selforganisation of matter over the 4.5 billion-year lifetime of the Earth. 


\section{Planetary evolution}

The primary source of all free energy in the universe is the original gravitational potential of matter when it appeared, evenly-spread, in the very early universe due to the decay of the earlier, unstable 'false vacuum' (Lineweaver and Egan, 2008). The second law of thermodynamics, when reinterpreted as a principle of maximum entropy production, stipulates that physical systems will tend to degrade gradients, and to develop systems to degrade them (and thus increase entropy, or disorder) more quickly (Dewar et al., 2014). However, as systems evolve there is typically a dialectic between mixing (the destruction of difference and gradients) and sorting (and thus the creation of new gradients). In the case of the early universe it was the gravitational clumping of matter that allowed the emergence of non-equilibrium, producing 'dissipative structures' such as galaxies, solar systems and eventually planets (Lineweaver and Egan, 2008). As part of the onward rush towards overall disorder and entropy, these dissipative structures (Prigogine and Stengers, 1984) create local order (highly correlated states) and new gradients, thus greater complexity and informational order, including new kinds of motion. The result at the scale of solar systems and planets is patterns that are specific and irreversible; planets are not just mixtures of different chemicals and states of matter, but have unique, divergent and emergent histories (DeLanda, 1992). The Earth thus has to be seen as a body which emerged, evolved and continues to evolve in an ongoing dialectic between the intensive (differences and gradients) and the extensive (form and structure).

Even before the formation of Earth, the accretion of the solar system from the solar nebula was already a great sorting which occurred through complex forms of mobility. A key 'saddle point' dividing the mobility regions of any solar system is the 'frost line', beyond which solar heat is weak enough for volatiles such as water, carbon monoxide and methane to freeze. This is line is positioned differently for different volatiles and around different stars, but in our own solar system is just outside the asteroid belt (Prockter, 2005). The eventual effect of this was to produce a complex but ordered planetary system with gas and ice giants outside the frost line and small rocky planets within. Inside the frost line, volatiles evaporate and smaller 'terrestrial' planets accrete from metals and heavier atoms; outside the frost line, giant planets form due to the greater number of solid particles and their ability to retain greater amounts of light gases (ibid.).

From a planetary mobilities perspective this is also a sorting of powers of mobility: the creation of bodies which have different powers to move things around within themselves. Planets, by definition, come to dominate their area of the solar system - and sometimes move to new stable orbits so they can do so (Soter, 2006). Isolated in the vacuum, planetary bodies follow the ellipses, parabolas and hyperbolas of gravitational motion, guided by the absolute memory of reversible Newtonian mechanics. Within themselves, however, their gravitational collapse into planetary bodies will produce energy gradients and far-from equilibrium conditions which favour the emergence of local order. Planets are bodies where the combination of fluid motion and solid durability creates information-rich pockets, where correlated states and motions can arise, endure and become more elaborate (Hidalgo, 2015). Astronomers talk about the 'Goldilocks' or 'habitable' zone around stars which enjoys the temperatures enabling the emergence of water-based life; but such zones are just one of the many self-organising 'mobility regions' in which planets can acquire different powers of internal motion. For planets and other astral bodies to 'learn' in this way - to have a unique and irreversible history of emergence - they need new ways of recording, recalling, learning and forgetting past mobilities. As Prigogine and Stengers put it, classical dynamic systems such as those governing planetary motion in what the ancients called the 'superlunary' world of the heavens already know everything they need to know in order to move along their orbits, and can never forget it (Prigogine and Stengers, 1984, pp. 305-6). But in the sublunary, far-from-equilibrium world of planetary becoming, what are needed for new mobility powers to develop are interacting systems of non-Newtonian memory: fluid memory (residing in the motion of flows, eddies or vortices), solid memory (in the stratigraphy, geodiversity and surface morphology of the solid earth, and in complex objects) and code memory (in DNA, culture with its arbitrary symbols or computational machines). 
If information is important for planetary mobilities, no less so is energy. Energy as defined by modern science cannot be created or destroyed, but it can be higher or lower in quality, as defined by its availability to do 'work' - in effect, to move macroscopic objects or create macroscopic gradients. However, the amount of work that can actually be done by the energy in any system (for example a pressurised container) depends on the difference between the energetic levels of that system and those of its environment. This difference is termed 'exergy', the amount of energy that is available to do work in relation to a suitable reference state, and this decreases as entropy increases. In the solar system, the primary reservoirs of exergy are the nuclear energy from fusible atoms in the sun and fissionable atoms in planetary bodies, the gravitational and kinetic energy of the solar system, and the residual thermal energy remaining from its formation (Hermann, 2006, p. 1689). From these primary reservoirs, energy cascades into secondary reservoirs, a cascade which within planets is conditioned by their particular history of self-organisation.

The outer planets - the gas giants Jupiter, Saturn and ice giants Uranus and Neptune - are so far from the sun that they receive little energy from it; instead, the motion of their atmospheres is driven mainly by the residual internal heat from compression and friction. Despite their coldness, the availability of different chemical elements with different melting points allows the outer planets and their moons to have rocks, atmospheres, seas and hydrological cycles, just based on different chemistry. Their residual inner heat is also sufficient to sustain vertical temperature gradients that ensure that even the extremely cold atmosphere of Neptune, which only receives $1 / 900^{\text {th }}$ of the solar energy per unit area that the Earth does, nevertheless has the most violent weather in the solar system (Suomi et al., 1991). The huge gravity wells of the outer planets also allow them to form highly complex satellite systems, with rings, shepherd moons that maintain ring boundaries and co-orbital moons that swap orbits (Spitale et al., 2006). As we explore the outer planets we are likely to find more and more unique mobility patterns in and around them.

Planets such as the Earth that formed and move within the frost line are very different. The higher temperatures closer to the sun do not mean more liquids and gases; instead, the greater power of the solar flux and solar wind strips volatiles away, making the inner planets smaller and more predominantly solid. The solar flux also dominates the energetics of their outer layers. The surface of the Earth, for example, receives nearly 2,000 times more energy from the sun than it does from the planet's interior (Davies and Davies, 2010). The inner planets are thus subject to a constant excess of electro-magnetic energy, and one which is unevenly spread across their spherical surfaces. Energy leaving the Earth system has to be equal to that arriving in it for its average temperature to remain relatively constant. But the majority of incoming solar energy works its way through the Earth system before it is converted to heat and radiated back out. Apart from the tidal movements caused by gravity, the major fluid motion on the earth - of the winds, the ocean and the wider water cycle - is driven by this solar energy, as radiative gradients produce temperature gradients, themselves producing pressure and density gradients, and thus motion (Kleidon, 2010). In the next section we will look at this fluid mobility.

\section{Fluid motion}

In fluids, whether liquid or gaseous, atoms and molecules are not locked into a rigid structure, so movement is prima facie easy; fluid flow is thus unsurprisingly a massive part of the Earth's mobility. Haff (2010) suggests that we measure the movement of mass in the Earth using a dynamic metric of 'mass action', calculated as the product of mass delivered, distance travelled between changes of direction and average speed, and measured in $\mathrm{kg} \cdot \mathrm{m}^{2} / \mathrm{s} .{ }^{1}$ If we exclude the direct flow of the Earth's core and mantle, the largest movements in the Earth as measured by mass action are advective flows within the atmosphere and ocean. Hermann (2006) estimates that of the 162,000 TW cosmic radiation reaching the Earth, $870 \mathrm{TW}$ - ten times the energy that enters the biosphere - is transferred to atmospheric kinetic energy, including wind, waves and the water cycle. The two largest motions of the atmosphere are the overturning 'cells' that make up the troposphere and the high, Westerly jet streams that flow along their boundaries. Motion in the oceans is comparable in 
scale. The five great oceanic gyres, caused by a combination of prevailing surface winds and the Coriolis effect, have a combined mass action of $4 \cdot 8 \times 10^{24}, \mathrm{~kg} \cdot \mathrm{m} 2 / \mathrm{s}$. The thermohaline circulation or 'ocean conveyor belt' follows a path that wanders around the world's oceans at various depths, caused by combination of wind-driven surface currents and density gradients in the water dynamically maintained by interaction with the sun and the land. It has a total mass action estimated as $3.0 \times 10^{24} \mathrm{~kg} \cdot \mathrm{m} 2 / \mathrm{s}$ (Haff, 2010, p. 1161).

As well as the reservoirs of air and water having their own internal mobilities, cutting across these is the water cycle, a closed cycle in which flow between ocean and land is crucial. Every year about $577,000 \mathrm{~km}^{3}$ of water ( $0.04 \%$ of the Earth's water) evaporates into the air from the Earth's surface $-1,580,000,000,000$ tonnes per day - nearly $90 \%$ of which comes from the ocean. Its average residence time in the air is 8-9 days, which means that at any one time the atmosphere is estimated to contain $12,900 \mathrm{~km}^{3}$ or $0.001 \%$ of the world's water; if it all fell at once it would form a $25 \mathrm{~mm}$-thick layer over the surface. $20 \%$ of precipitation falls on land (albeit very unevenly); the Earth's rivers, which at any time only hold $0.0002 \%\left(2,100 \mathrm{~km}^{3}\right)$ of global water, cumulatively carry $40 \%$ of land precipitation to the oceans, by renewing their water every 16 days (Shiklomanov, 1993). They thus constitute a fifth great fluid motion system, just four orders of magnitude lower in mass action than the four mentioned above. The largest technological fluid flow system, long-distance pipelines, is smaller than all these - much smaller in mass moved per second, though because of the distances travelled, in mass action it is beginning to rival rivers and precipitation taken as separate mobilities (Haff, 2010, p. 1161).

Fluid motion is not just quantitatively significant, but provides the main mechanisms for creating gradients and sources of free energy within the Earth (Kleidon, 2010). However, fluids lose macroscopic conformational information, the information stored in the arrangement of parts: even when their mass moves advectively as whole, fluids deform as they move; if gaseous, they also compress and expand. What moves to a new location is mass and energy, including any variation in chemical composition and heat, but little else. Neither can fluids by themselves remember where to go; inertia tends to be quickly dissipated by viscosity or turbulence, and the motion of each individual molecule is determined by the actual internal gradients at that time and place. When applied energy gradients enable fluids to form far-from equilibrium vortices such as Bénard cells in heated liquids, or cyclones in the tropical atmosphere, complex choreographies of motion can arise at macroscopic scales of centimetres and kilometres (Prigogine and Stengers, 1984, p. 144), extending fluid memory to timescales of days; even small vortices can help fluid motion to remember initial conditions (Zhou and Antonia, 1995). However, fluid motion is intrinsically more forgetful, and on its own shows limited capacities for supporting the emergence of new forms of order, and thus new and complex kinds of mobility.

\section{Solid motion}

The movement of solids may be more interesting than that of fluids, but it is also more difficult. The very feature of solids that enables them to carry conformational information means that all atoms have to move together, requiring huge forces. Solids are also on the whole denser, so heavier per unit volume; furthermore, on the terrestrial surface, the Earth's gravity produces friction between object and ground, which tends to keep solids in place. So it should not be surprising that solid movement is much smaller than fluid motion in the Earth. Even the largest systems of solid movement in the Earth have mass action that is 4 or 5 orders of magnitude smaller than the largest involving fluids. For solid motion, the largest mass action occurs in cases where massive solid entities are moving very slowly due to an applied force, such as continental drift, sea-floor spreading and Antarctic glacial flow (Haff, 2010, p. 1161). After that, solids move more easily when they are 'discretised' - broken up into smaller pieces. When broken up into small enough particles, solids can hitch a ride in the advective flow of fluids, with the mass action of river sediment and aeolian dust estimated at $5.0 \times 10^{17}$ and $2.0 \times 10^{17} \mathrm{~kg} \cdot \mathrm{m} 2 / \mathrm{s}$ respectively (ibid.). They can also use the enveloping 
fluid to reduce friction, for example in submarine landslides. Under certain conditions discretised solids can themselves flow and move in fluid-like ways - in avalanches of sand and rock, for example.

In the evolution of the Earth there have been a number of crucial 'bifurcations', irreversible revolutions which shaped the capacities of its internal parts to move in different ways (Lenton and Watson, 2011). These include the emergence of life, and later that of animals. On an Earth without life, the remainder of the incident solar energy that is not converted into fluid motion of air and water would be either scattered back into space as electro-magnetic radiation, or converted to heat. The biosphere now captures a small but significant amount of that energy. Of the 86,000 TW of solar exergy that reaches the Earth's surface, 10-20,000 TW falls on plants and algae. Some of this simply powers evaporation from plant surfaces, feeding back into the energetics of the climate system. But $0.5-1 \%$ of it is captured by photosynthesis, resulting in an energy flow into the biosphere of about 90 TW (Hermann, 2006). If we simply had a biosphere consisting of photosynthesising autotrophs, this cascade of solar energy would no longer be converted into significant motion, but largely used for organic maintenance, growth and reproduction. But the emergence of animals changed that.

Haff (2012) argues that animals (and their later offshoot technology) overcame the challenges to large-scale solids transport in the Earth through three main innovations - internal power, rotary motion and infrastructure. The first innovation involved not relying on ambient energy alone but having an onboard store of chemical energy that can power motion. The abiotic motion of fluids or suspended particles relies on ambient gradients of gravity or pressure; singlecelled organisms gain their energy from sunlight or 'osmotrophically', by absorbing chemicals through their membrane, so are also in a sense dependent on ambient energy sources. But about 2 bya (billion years ago) some single-celled organisms learned to engulf particles or other organisms, processing them internally for their nutrients (Lenton and Watson, 2011). Around 0.6 bya animals took this further; through multicellularity and cell-differentiation they became able to grow multiple tissues, to develop a tube from mouth to anus that enables them to process and absorb ingested food, and to store as sugars and fats any energy that was not immediately needed (Butterfield, 2011).

This ability to absorb and store larger quantities of nutrients both enabled and required new forms of mobility. For subaerial, terrestrial motion, larger solid moving entities have to overcome the problem of friction - the second major challenge to solids transport that Haff (2012) identifies. Haff points out that the innovation of rotational motion (limb motion or undulation in animals, wheels in machines) turned friction from a problem to an asset. Studies of animal locomotion show that all animals have evolved to move in a way that maximises the proportion of total expended energy that is actually used to propel the animal's body forward (Bejan and Marden, 2006), within the constraints of evolution, lifestyle and environment.

In quantitative terms as measured in units of 'mass action', the motion of these new animals was and remains tiny compared with that of the fluid compartments of the Earth or their suspended solid particles. But in a qualitative sense it was hugely significant, representing a new stage in the arising of 'form' in the Earth (Szerszynski, 2016). Animal mobilities represented a new 'needful freedom' to add to that of the metabolic relationship between the organism and its environment (Jonas, 2001): animals moved to eat - but also ate to move. Their presence also brought about a new relation in the earth - that between predator and prey. This opened up a whole new 'phase space' for life in the Earth with an open-ended, evolving set of gradients on which different life forms became arranged - speed, size, hardness, alertness, digestibility and so on. This in turn produced a huge acceleration in the evolutionary 'arms race' (Lenton and Watson, 2011, p. 286), and propelled the Earth towards its current dynamic, self-regulating biosphere with vastly greater amounts of standing biomass and internal recycling of elements (Butterfield, 2011) .

This energetically open but materially closed 'Gaia' of the Phanerozoic aeon (the last 0.5 billion years) has made the Earth even more effective in degrading exergy. This acceleration of entropy production has involved the emergence of new, terrestrial levels in the energetic cascade from the solar system's primary energy reservoirs mentioned above. The fraction of incident solar 
exergy that is directed into the biosphere is first captured by photosynthesising plants and algae; however, these 'autotrophs' or 'primary producers' form only the 'lowest' trophic level of the biosphere, on which feed primary consumers (herbivores), then secondary consumers (small carnivores) and sometimes other levels before we arrive at peak predators. In each trophic level the majority of the energy coming in is used to maintain the metabolism of the organisms and only the remainder for growth and reproduction. This, combined with the limited efficiency of assimilation, means that each level can only capture an average of $10 \%$ of the energy of the previous level, so that as one moves up trophic levels populations and total mass and available energy decreases (Pauly and Christensen, 1995). It is thus not surprising that the systems of non-human living solids transport with largest mass action according to Haff's calculations are migrating animals on relatively low trophic levels and in low-resistance environments - whales, fish, birds and caribou - each of whose cumulative mass and distance travelled allows them to rival in mass action all other examples of solids movement not propelled by flows of air and water (Haff, 2010, p. 1161).

Yet even the latter are now rivalled in mass action by the main technological mobilities systems - maritime shipping, rail, trucks and automobiles (Haff, 2010, p. 1161). In sheer energetic terms this has clearly only been possible by the accelerating mining and combustion of fossil-fuel energy reserves. As well as capturing an estimated $24 \%$ of the net primary production of the terrestrial biosphere (Haberl et al., 2007), or about 16 TW of energy (Hermann, 2006, p.1692), humans also now tap into geological reserves of energy at a massive and growing rate. Humans currently generate 5.1 TW from burning oil, 3.6 TW from coal and 3.2 TW from gas, from estimated geological reserves totalling $430 \mathrm{ZJ}$ (Hermann, 2006). In terms of the payload being carried, humantransported mass has historically been mainly biomass: fuel and food. However, in the developed world this has recently being overtaken by the flow of minerals and metals, as advanced (and emergent) economies move towards building and maintaining a growing infrastructure of buildings, roads and durable goods; it is estimated that the standing stocks of materials in such structures amounts to several hundred tonnes per person in industrial societies (Schaffartzik et al., 2014). Global mining and quarrying are estimated to move more than 57 billion tons per year - more mass than is moved either by glaciers or water erosion (Bridge, 2009).

In human-induced mobilities of biomass and minerals, a crucial role is played by 'motilisation' - the transformation of non-motile local geological, ecological or economic resources into materials capable of advection in global currents of flow. This partly involves the discretization of biological or geological entities in order to make them easier to move. As Lewis Mumford put it, in the modern period 'the methods and ideals of mining became the chief pattern for industrial effort throughout the Western world. Mine : blast : dump : crush : extract : exhaust' (Mumford, 1934, p. 74). But at the same time it involves converting things in a qualitative sense into abstract and exchangeable 'material'. This is what Andrew Feenberg calls 'primary instrumentalisation': the decontextualisation of 'raw materials' out of their naturalistic context (rocks in the ground, or trees in a forest) and their reduction to primary qualities such as chemical composition, brittleness, homogeneity and strength (Feenberg, 1999, pp. 203-5). Motilisation of raw materials and their incorporation into global advective flows can also of course involve forms of cultural and political violence (Tavares, 2013).

\section{Mobility regions}

We saw in the section on planetary evolution that the solar system can be divided into different regions of space where a specific set of physical characteristics gives rise to particular forms and patterns of mobility. The body of the Earth, too, can be divided into different mobility regions. In this section I will focus on the kinetics and energetics of mobile solid entities (whether abiotic, biotic or artefactual) in different 'mobility regions' - some characterised by a single medium such as air, water or loose earth, and some at the boundary between different media.

Firstly, then, some solids move within a single medium. As we have seen, some of the largest solid flow in the Earth is the passive transport of suspended particles such as river sediment and 
aeolian dust. But many self-powered objects also move in the midst of air or water-birds and aeroplanes, fish and submarines. Because of the low density of air, flying requires lift as well as thrust and so is more costly per unit time than either swimming or terrestrial motion (Goldspink, 1977a 164-5); however the low viscosity of air allows faster speeds so flying is more energetically efficient per unit distance. Animals make up the vast majority of marine biomass (Butterfield, 2007, p. 48); marine animals can move with great efficiency at low speeds, especially when using 'lift' forces to produce forward motion. However, drag in water increases with the square of speed, so, unlike motion in air, motion in water has optimum speeds in terms of energetic cost. Drag is also increased further by the presence of buoyancy organs (Alexander, 2003, p. 310), and oxygen levels in water are low, so aquatic animals only engage in fast swimming in bursts (Goldspink, 1977a 165). Some animals engage in 'fossorial' motion under the ground, but energy costs with this form of movement tend to be high (Trueman and Jones, 1977).

Secondly, however, some solid mobility occurs on the boundary between media-between gaseous and solid (on or near the subaerial land surface), liquid and solid (in the benthic layer of water bodies), or gaseous and liquid (on the subaerial surface of a body of water). Abiotic motion in these boundary zones includes gravitational motion (landslides and mudslides) and fluid-powered motion, such as the reptation (creeping) and saltation (jumping) of subaerial soil and sand, or windblown debris floating on water. Such powers of motion are profoundly shaped by the velocity gradient across the 'boundary layer' close to the surface, within which the velocity of the fluid as one approaches the surface starts to approach that of the surface (Vogel, 1994, pp. 174-203). By contrast, self-powered entities moving on the boundary between media, whether biotic or technological, are subject to very different constraints, as they try to move more efficiently by exploiting the different properties of the respective media. Swimming at the fluid-fluid water-air boundary is less efficient than subsurface swimming, since surface swimmers produce wakes which dissipate energy and tend to use the less-efficient terrestrial styles of motion (Goldspink, 1977a 158). Massive containerships are better able to exploit the energetic properties of surface swimming, but the economics of freight delivery forces them to go faster than would be optimal; above 14 knots, energy use rises exponentially, since ships are constantly climbing their bow waves (Vogel, 2013, p. 277). However, the Earth-air boundary is probably the most significant for selfpropelled solid motion on the Earth.

On the subaerial terrestrial surface, animals use their limbs or sinuous motion to take advantage of the combination of high friction between their body and the 'ground' (broadly conceived), and the low viscosity and high oxygen content of the air. Locomotion techniques can be cursorial (walking, running), saltational (jumping, hopping) or arborial (climbing, swinging). Terrestrial limb motion itself uses low energy thanks to the low mass of limbs and the use of elastic tension to store unused energy in each swing and reuse it in the next. However, energy use per unit time in terrestrial motion is higher than that of swimming (Goldspink, 1977a, p. 164), though larger terrestrial animals are more energy efficient (Goldspink, 1977b, p. 78).

Technological mobility on the land surface was not a hugely significant phenomenon until the advent of motorisation and sophisticated transport infrastructures. Wheeled transport initially emerged in order to make better use of animal (including human) energy. Two-wheeled carts and chariots were developed in Asia for use in agriculture, warfare and ceremony (Mazoyer and Roudart, 2006, p. 445), and were the basis for the later development of the cumbersome European heavy 'wagon', used for freight and sometimes passengers. Lighter 'carriages' for passengers emerged mainly in $15^{\text {th }}$ century Hungary, soon spreading and diversifying across Western Europe and then North America; their use, like that of the earlier chariot was largely elite and driven by processes of social distinction (Piggott, 1992). Mechanised land vehicles such as the train, automobile and truck evolved, morphologically speaking, from the carriage, but this continuity belies the way that the motorisation of vehicles triggered a 'major transition' in the evolution of terrestrial motion.

Firstly, the shift of energy source from animal feed to massive stocks of energy-dense fossil fuels meant that calculations of energetic efficiency (whether explicit or tacit) became dominated by 
the amount of energy expended in obtaining and refining the fuel, rather than the amount that the fuel contained, encouraging far greater energy use (Hall et al., 2014). Secondly, the main driver in land transport, measured by mass and distance, became now not agricultural labour or social status but the needs of a commercial society constituted of dispersed land-based settlements, with populations undergoing a growing division of labour and increasingly dependent on distant natural resources (Zalasiewicz et al., 2014, p. 44). Thirdly, the spread of motorised land vehicles necessitated the overcoming of 'form-resistance' due to irregularities and obstacles on the land surface (Haff, 2010, p. 1161), since existing roads were only suitable for animal motion or large, slow wheels; the speed and reliability offered by the new vehicles only became possible with the building of extensive infrastructure, with railroads in the $19^{\text {th }}$ century and then metaled roads and highways in the $20^{\text {th }}$ (Grübler, 1990).

\section{Mobility situations}

Even where different entities are moving within the same spatially defined mobility region, they can nevertheless enjoy very different powers of motion, due to their experiencing a different balance between the various physical forces that act on matter. A series of 'dimensionless numbers' can be used to characterise the balance of different forces in particular 'mobility situations' - particular couplings of size, mobility and environment. The entire mobility 'phase space' within a given mobility region can be seen as constituted by a range of mobility situations (or 'flow regimes'), some functioning as self-reinforcing basins of attraction, others forming unstable 'manifolds' between them. For example, Bagnold numbers (viscosity versus grain inertia in granular flow) characterise different mobility situations in mudslides, avalanches, and flows of sand, concrete or grain. Froude numbers, which measure the relative predominance of gravity and inertia, can be used to understand the sorting of particles in air and water, gait transition in animals, and the different mobility situations of ships and other surface swimmers going at different speeds in relation to their size. The form-resistance in land-based mobility discussed above is also a function of relative size of moving entity and obstacle. But perhaps the most crucial dimensionless number in planetary mobilities is the Reynolds number, which concerns the balance between viscosity and inertia.

The Reynolds number is crucial for motion within a fluid medium, whether passive (with the flow) or active (against it). Crucially, the Reynolds number, like many other dimensionless numbers, applies to a whole mobility situation rather to a particular mobile object or medium (McMahon and Bonner, 1983, p. 96); thus, a low Reynolds number (what is called Stokes flow) might be produced by one or more of a number of factors: small scale (e.g. swimming bacteria or sperm), highly viscous matter (e.g. lava flow) or slow speed. With Reynolds numbers greatly below 1 , viscosity and friction is powerful and inertia is negligible. In this mobility situation it is not possible to swim like a fish or whale, thrust then glide; any moving entity has to keep its power on or it will stop. Fluid flow is slow, linear, and uncannily reversible; mixing is almost impossible (Vogel, 1994, pp.331-61). This physics makes locomotion very difficult: the organism has to break with time-reversible symmetry so small single-celled organisms had to evolve non-reversible movements, such as whip-like flagella turned on rotary axles (Purcell, 1977).

However, even in regions that smaller entities would find viscous, if entities are large enough, or move fast enough relative to the medium, then they will inhabit a high-Reynolds, inviscid flow regime in which inertia dominates and viscosity becomes irrelevant. Birds and fish live at high Reynolds numbers, and planes higher still (McMahon and Bonner, 1983, p. 95). Here moving objects can use the weight of their body to continue forward motion, but outside the laminar boundary layer of fluid right next to the moving object, inertia produces eddies undamped by viscosity, producing further eddies that cascade down to smaller scales where they are degraded away by friction [REF XX]. In this flow regime (for example in water at medium speeds, or in air at high speeds) morphology becomes extremely important because of drag and lift - hence the convergence of form between planes, submarines and dolphins. 
Amongst other things, the Reynolds number affects the possibility of passive, suspended transport. Because they are gaseous, atmospheres have densities and viscosities that are much more variable than those of liquids. The air of the Earth is intermediate in density and viscosity between the thick atmospheres of Venus and Titan (the largest moon of Saturn) and the thin atmosphere of Mars; amongst other things, this affects what these worlds can do to mobilise ground particles. On Earth, soil particles, depending on their size, inhabit different mobility situations in relation to the fluid flow of the atmosphere. Those below $70 \mu \mathrm{m}$ in diameter or below can be lifted and suspended in the air - smaller ones for weeks, travelling for thousands of kilometres; those between around 70 and $500 \mu \mathrm{m}$ can be made to saltate (jump), whereas those above about $500 \mu \mathrm{m}$ can only reptate (make small hops) or creep along the ground (Kok et al., 2012, p. 2). The relatively low Reynolds numbers on Earth and Mars also means that saltating particles fall fast, 'splash' and dislodge others, easily creating a metastable haze of suspended particles, and can produce complex dune shapes. Venus and Titan by contrast have thick atmospheres and simple unidirectional winds; on these worlds particles of the same size inhabit a different flow regime with lower Reynolds numbers, more like that under water. Dust particles can only be lifted small heights and are less likely to reach higher, faster winds; they also fall slowly, producing no splash (ibid., p. 23).

But as well as being important in defining immediate mobility situations at different scales, the kinetic and energetic differences captured by dimensionless numbers such as Reynolds numbers can also be 'locked in' to patterns of planetary mobility, producing bifurcations that go on to structure the kinds of motion available to the parts of the planet. Perhaps the most significant example of this is the role played by the viscosity of water in the establishment of the Earth's five kingdoms of life (archaea, bacteria, animals, fungi and plants). Because bacteria and archaea live at very small scales, and inhabit a low-Reynolds regime where water is viscous and inertia is irrelevant, movement after resources is energetically costly; these organisms thus continue to follow a strategy of economy, staying small, simple and numerous. In the Phanerozoic world, by contrast, macroscopic, multicellular life (plants, fungi and animals), escaped the Stokes viscosity regime through sheer size and this opened up new possible strategies based on more complex bodies. Both plants and fungi follow strategies which focus on being able to alter their shape in response to environmental conditions, and being resilient in the event of losing parts. Animals adopted a different evolutionary strategy again, one that combined a fixed shape with mobility, thus prioritising flexibility of response to different signals in a shifting environment (Yafremava et al., 2013). Once these different strategies established a new phase space for macroevolutionary development, the trade-off relations between them created positive feedback loops that 'funnelled' lineages further into these divergent strategies. A similar analysis of mobility situations using dimensionless numbers could be used to understand the establishment of different lineages of mobile technological objects, which are also subject to their own evolutionary processes of lock-in, but there is no space for this here. Now we must turn to one remaining feature of some forms of mobility in the Earth, ones which seem to challenge symmetrical modes of description and explanation.

\section{Mobility gratuity}

Any comprehensive theory of planetary mobility, however committed it is to explanatory symmetry, cannot ignore features of technological mobilities that seem to defy a purely physical explanation and require the introduction of concepts such as 'mind', 'purpose' and 'intelligence'. Haff captures these features very well when he talks of 'transport of complex payloads with persistent memory, displacement of these payloads independent of geophysical fluid flows and topographic slope, and spatially accurate delivery to fixed but arbitrary destinations' (Haff, 2012, p. 155) - and we might also add the delivery of information using arbitrary material or energetic substrates.

One way to account for the presence of these 'complex' mobilities in the Earth would be to try to identify the 'critical steps' necessary for their historical development, such as the prior emergence of intelligent living beings. ${ }^{2}$ However, while such an approach is useful, there is a danger 
that it universalises the specific steps that were de facto involved in the development of complex mobilities in the Earth. In order to avoid an Earth-bound 'observer bias' in our consideration of such issues we need to develop a 'speculative planetology' that is more imaginative about the possible paths that could be taken in the self-organisation of matter in planetary evolution (Szerszynski, forthcoming). Two counterintuitive features of such an approach are relevant here: firstly, that attending very closely to the specific trajectory of development undergone by the Earth can help to identify more general patterns and thereby alternative counterfactual possibilities, and secondly, that following Haff's strategy of downplaying rather than accentuating conventional distinctions between 'natural' and artificial entities, and between intentional and unintentional motion, can actually help us better understand what is so distinctive about certain forms of technological mobility.

The overarching concept that I want to use to capture all the remarkable features of technological mobility which Haff identifies is 'mobility gratuity'. I develop this notion with reference to Jacques Monod's analysis of the nature of life. Inspired by Erwin Schrödinger's (1944) prescient insight that the genetic code must take the material form of an 'aperiodic crystal', Monod (1972) suggests that, with the emergence of the genetic code, crystalline structures themselves gained a new freedom in which chemical affinity was uncoupled from physical function - in biosemiotic language, they gained a new 'semiotic freedom' (Hoffmeyer, 1996). Using the example of how inducer molecules regulate the expression of genes by altering the shape of regulatory proteins that bind to the gene, Monod draws attention to 'the independence, chemically speaking, between the function itself and the nature of the chemical signals controlling it'. He suggests that this 'gratuite' had the effect of 'giving molecular evolution a practically limitless field for exploration and experiment' (Monod, 1972, pp. 78, 79). I will argue that an analogous process is occurring here: in generating complex mobilities that involve 'arbitrary' relations between origin, mobile entity and destination, the Earth succeeds in opening up new kinds of gratuity in the phenomenon of mobility.

Here I will identify three forms of mobility gratuity, all of which can be found in certain kinds of abiotic or biotic motion, but have arguably been most effectively stabilised and combined in the technological domain. The first is the gratuity between the magnitude and direction of motion. Generally, in abiotic mobility situations these two are inseparable - indeed, that follows from the way that energy and force are defined in the physical sciences. As discussed above, abiotic objects or bodies of fluid (if they are not releasing chemical energy, or latent heat through state change) move (we would say) 'passively' under the influence of external gradients which provide both locomotive power and direction of motion. Thus pebbles rolling down slopes obey the law of gravity; molecules or larger objects within fluid flows (air, water or magma) are driven by local density gradients. If the force is greater on one side of the molecule or object than the other, thus giving it potential energy, it will move in order to lose that potential energy, thus converting it to motion.

However, some forms of mobility exhibit an uncoupling of (scalar) power and (vector) direction of motion. Intimations of this kind of gratuity are observable in certain classes of abiotic phenomena wherein mobile things create a partial liberation from local, ambient gradients by producing their own internal gradients through autopoietic self-organisation. For example, the 'debris flow' and 'turbity flow' regimes of submarine landslides help them to transport vast amounts of sediment far away from continental shelves (Leeder, 2011, p. 171), and tropical cyclones organise their own internal gradients and create huge amounts of correlated motion over many days, by extracting thermal energy from ocean evaporation and coupling vertical updraft with horizontal circulation (Marks, 2003). However, such macroscopic metastable formations are shortlived, and their gross motion still determined by the larger-scale gradients around them. It is in biological and technological entities that this form of gratuity is most effectively sustained and exploited.

In the motile animal, power-direction gratuity has been functionally and morphologically stabilised in the differentiation between the animal's internal (generally chemical) power store and its organs of locomotion. Powered motion in single-celled organisms, when combined with sensitivity to environmental stimuli, enabled them to engage not just in random, undirected 'kinesis' 
but also in directed 'taxis', moving up or down gradients that are only indirectly related to the energy powering their motion, such as those of chemical concentrations (chemotaxis), light (phototaxis) or oxygen (aerotaxis) (Nealson, 2011, pp. 48, 51). More complex, multi-cellular animals, under the pressures of natural selection, developed far more complex behavioural sequences that perform various functions within their lifecycle and the wider ecology (Breed and Moore, 2012, pp. 257-62). In technological mobilities this particular kind of gratuity is even more visible, with separate mechanisms for propulsion and steering (such as accelerator and steering wheel). Indeed, viewed through this framework, the forms of animal and technological mobility that stand out as interesting are those that do not so clearly follow this pattern of gratuity between power and direction: limbless animals such as snakes and eels, or forms of transport relying on ambient energy such as ballooning, downhill skiing and surfing.

A second form of gratuity in mobility is that between carrier and carried. Haff suggests that the vehicle-payload split so taken for granted in modern transport systems partly derives from the fact that, unlike in fluid transport, solid payloads naturally maintain their shape and therefore separation from the mechanism that is transporting them, but also argues that it constitutes an 'innovation' that has been necessitated by the functional needs of the Earth's technosphere (Haff, 2012, pp. 152-3). However, viewed as a form of mobility gratuity, the distinction between carrier and carried can be seen as a wider recurrent feature of the evolution of planetary mobilities in the Earth. The shaping of the Earth's solid form has depended crucially on the division between fluid advective flows and their solid payload of suspended particles. The ability of rivers and winds to motilise particles, to mix and to sort, to deliver and deposit, and thus to turn the surface of the Earth into the complex generative region that it is, depends on the distinction between carrier and carried. Even in the case of a chemical solution, or water vapour in the air, chemical difference allows us to talk of a difference (if not always a chemically arbitrary relation) between carrier and carried, evidenced by the possibility of the chemical payload precipitating as a 'deposit'. The emergence of self-propelled animal motion constituted a shift of emphasis within solid mobility in the Earth from carrier-carried gratuity to power-direction gratuity; however, there are still countless examples of animals having organic 'passengers', from plant seeds and bacteria to internal symbionts and parasites, even before humans start domesticating horses and camels. But with the establishment of what we might call the 'kingdom of machines' the relation between carrier and carried is taken to new levels of arbitrariness, epitomised morphologically in sealed, standardised containers such as the Wardian case in the nineteenth century (Pawson, 2008) and the intermodal freight container in the twentieth (Birtchnell et al., 2015; Levinson, 2006). This form of gratuity is as crucial as powerdirection gratuity for today's global flows of freight, as it allows the meshing of long-distance advection between continents (by marine shipping and air), advection between cities (by truck and train) and local diffusive flow (by van).

A third form of gratuity manifest in technological mobility is that between matter and information. As described above, complex objects such as storms, organisms and artefacts contain 'conformational' information in the arrangement of their parts, and when we say that such entities move, we typically mean that this arrangement also moves. With dissipative fluid structures such as hurricanes, conformational information consists partly in correlated motion, and it is this metastable arrangement that persists and moves as different molecules pass through it. With solid objects, by contrast, shape is correlated position, and with complex objects there can be a highly complex set of correlations between its parts at different spatial scales. However, some technological forms of mobility have opened up a gratuity between the material and conformational poles of this particular dimension of mobility. Such modes of mobility we typically call 'media'. Thus visual representations such as plans, paintings, drawings or models, and latterly photographs and film, or written descriptions or instructions, enable the transfer of at least part of the conformational information of complex entities and assemblages onto other material objects, which can thus travel without the original matter. ${ }^{3}$ With aural, electronic and optical forms of transmission, conformational information can move without any baryonic matter ${ }^{4}$ moving with it at all, before it might be turned 
back into spatial arrangement. With the advent of 3D printing we may see a shift away from the transport of complex objects towards streams of raw materials on the one hand and digitised information on the other (Mohr and Khan, 2015).

It is perhaps more difficult but nevertheless possible to identify non-technological manifestations of this form of mobility gratuity. Until the arrival of human technologies, planetary bodies, although they each lie at the bottom of their own gravity well, seem to have been better at exchanging mass (in the form of meteor fragments) than information. The development of living things and their various endosemiotic (inner) and exosemiotic (externally oriented) significatory processes represents a major transition in the capacity for information to move without its accompanying matter (Hoffmeyer, 1996). However, limited forms of intra-planet matterinformation gratuity also occur more widely in the case of bottle-necks or pinch-points in the transmission of form, where a small and morphologically simple 'seed' can under the right conditions reconstruct the original object. For example, given the right chemical conditions, a crystalline fragment can reproduce the form of an original crystal, as molecules from the surrounding fluid arrange themselves geometrically in the energetically lowest state (Pimpinelli and Villain, 1998). Far greater 'bandwidth' is available in the reproduction of eukaryotic organisms plant, animals, and fungi - where the genetic information contained within a seed, egg or spore is sufficient for the recreation of an entire living entity (Margulis, 1998: 70) - and the behavioural inheritance of an individual organism sufficient for the potential recreation of dwellings and physical niches. In all of these cases, the capacity for the conformational information to move is distributed in different ways between the entity as 'source' and the environment as 'channel' or enabling condition (Oyama et al., 2001b).

We have seen in this section that technologically mediated mobilities often exhibit forms of 'gratuity', and that these can be seen as a manifestation of a wider phenomenon in planetary selforganisation. However, it is also important to clarify that entities that engage in more 'complex', gratuitous forms of mobility are not simply more 'liberated' from their environment, as direction of travel might be said to be liberated from source of energy, payload from vehicle or information from matter. Instead, forms of gratuity often seem to involve a sharing and distributing of powers between the mobile entity and its environment, in a way that echoes the notions of 'extended inheritance' and 'niche construction' in evolutionary biology (Odling-Smee et al., 2003; Oyama et al., 2001a). The phenomenon of mobility infrastructure and delivery systems can be seen as a particular manifestation of this wider dynamic. Haff $(2010 ; 2012)$ points out that mobility infrastructure is not confined to the human and technological worlds: not just roads and railways but also rivers and animal paths are alterations of the environment which serve to reduce friction and/or 'form resistance' due to rough ground. But infrastructure is not just about energetics: moving faster, and more efficiently; it can also be about information and gratuity: knowing where and how to move. The ability of individual entities to move in complex ways on the Earth becomes an achievement not of that entity alone, but one built up through repeated motion within a 'taskscape' which is itself, in part, a sedimentation of all such prior movements (Ingold, 2000, p. 195).

\section{Conclusion}

The planets of our solar system move with what, at human timescales, seems like perfect regularity; within planets, by contrast, we find very different, 'sublunary' forms of mobility (Prigogine and Stengers, 1984, pp. 305-6). In the dense media of fluid planetary compartments, and under farfrom-equilibrium conditions, the perfect, reversible god-like motion of the planets is all but impossible; inertia becomes not a form of memory but a source of forgetting, of dissipation, as moving entities diverge from their path in what Lucretius called the 'clinamen', losing not just their direction but their very motion in cascading eddies (Serres, 2000). Yet this forgetting also forms the basis of new and very different powers of motion and memory, just as it did in the early solar system as planets and moons formed themselves out of the solar nebula. The cascade of energy through the solar system and its constituent bodies generates new forms of self-organisation; the play between 
mixing and sorting, intensive difference and extensive form, means that as gradients are applied and dissipated, new gradients and new energetic levels are brought into being. Planets become historical entities, undergoing bifurcations in their development which condition their powers of motion and memory, and their possibilities for further development.

As we have seen in the case of the Earth, planets also develop their own 'mobility regions' within themselves; within these regions, material and energetic conditions give rise to particular possibilities for mobility. At different scales and speeds, mobile objects in these regions also inhabit different 'mobility situations', due to different balances of forces. Mobilities also 'tune' together or even clash - as the delivery of matter, energy or information in one mobility system intersects with that of another. And sometimes these dynamics are 'locked-in' as historically contingent bifurcations that condition the planet's future development, including its emergent powers of mobility.

I have also argued that complex features of technological mobility that might seem unique and unprecedented in the Earth can be understood as manifestations of a more general phenomenon of 'mobility gratuity', a relative uncoupling of different aspects of motion that can arise under planetary conditions. It may be true that the particular stabilisations and combinations of forms of gratuity that we see in technological mobility were partly driven by the contingent needs of human economies at particular times and places. However, viewed in the light of the long selforganisation of the solar system, they could also be seen as manifestations of more general powers of planetary mobility - and perhaps as hinting at radical new possibilities for its development, both here in the Earth and in other planets.

\section{Acknowledgements}

I would like to thank Monika Buscher, Gail Davies, Charlie Gere, Steve Hinchliffe, Tim Lenton, Mimi Sheller, David Tyfield and the anonymous referees for comments on early drafts of this paper, and Peter Haff for a lively and stimulating email exchange about its ideas.

\footnotetext{
Notes

${ }^{1}$ Mass action is of course not a wholly reliable indicator of the relative significance of different kinds of mobility occurring on a topologically complex planet or involving informationally rich entities.

2 For an example of such an approach to estimating the likelihood of the emergence of 'intelligent life' or 'observerhood' on a planet, see Watson (2008).

${ }^{3}$ On forms of inscription and technological artefacts as an externalisation of memory, see Stiegler (1998).

${ }^{4}$ Baryonic matter is 'normal' matter, composed of atoms, as opposed for example to neutrinos or free electrons.
}

\section{$\underline{\text { References }}$}

Alexander, R. M. (2003) Principles of Animal Locomotion (Princeton, N.J.: Princeton University Press). Bejan, A. \& Marden, J. H. (2006) Unifying constructal theory for scale effects in running, swimming and flying, Journal of Experimental Biology 209(2), pp. 238-48.

Birtchnell, T., Savitzky, S. \& Urry, J. (2015) Cargomobilities: Moving Materials in a Global Age (1 Edition. edn).

Breed, M. D. \& Moore, J. (2012) Animal Behavior (Amsterdam: Academic Press).

Bridge, G. (2009) The hole world: spaces and scales of extraction, New Geographies 2, pp. 43-8.

Butterfield, N. J. (2007) Macroevolution and macroecology through deep time, Palaeontology 50(1), pp. 41-55.

Butterfield, N. J. (2011) Animals and the invention of the Phanerozoic Earth system, Trends in Ecology \& Evolution 26(2), pp. 81-7. 
Cresswell, T. (2013) Friction, in: P. Adey, D. Bissell, K. Hannam, P. Merriman \& M. Sheller (Eds.), The Routledge Handbook of Mobilities (London: Routledge), pp. 107-15.

Cresswell, T. \& Martin, C. (2012) On turbulence: entanglements of disorder and order on a Devon beach, Tijdschrift voor Eeconomische en Sociale Geografie 103(5), pp. 516-29.

Davies, J. H. \& Davies, D. R. (2010) Earth's surface heat flux, Solid Earth 1(1), pp. 5-24.

DeLanda, M. (1992) Nonorganic life, in: J. Crary \& S. Kwinter (Eds.), Zone 6: Incorporations (New York: Urzone), pp. 129-67.

Dewar, R. C., Lineweaver, C. H., Niven, R. K. \& Regenauer-Lieb, K. (eds.) (2014) Beyond the Second Law: Entropy Production and Non-Equilibrium Systems (New York: Springer).

Doherty, C. (2015) Agentive motility meets structural viscosity: Australian families relocating in educational markets, Mobilities 10(2), pp. 249-66.

Feenberg, A. (1999) Questioning Technology (London: Routledge).

Goldspink, G. (1977a) Energy cost of locomotion, in: R. M. Alexander \& G. Goldspink (Eds.), Mechanics and Energetics of Animal Locomotion (London: Chapman and Hall), pp. 153-67.

Goldspink, G. (1977b) Muscle energetics and animal locomotion, in: R. M. Alexander \& G. Goldspink (Eds.), Mechanics and Energetics of Animal Locomotion (London: Chapman and Hall), pp. 57-81.

Grübler, A. (1990) The Rise and Fall of Infrastructures: Dynamics of Evolution and Technological Change in Transport (Heidelberg: Physica-Verlag).

Haberl, H., Erb, K. H., Krausmann, F., Gaube, V., Bondeau, A., Plutzar, C., Gingrich, S., Lucht, W. \& Fischer-Kowalski, M. (2007) Quantifying and mapping the human appropriation of net primary production in earth's terrestrial ecosystems, Proceedings of the National Academy of Sciences 104(31), pp. 12942-7.

Haff, P. K. (2010) Hillslopes, rivers, plows, and trucks: mass transport on Earth's surface by natural and technological processes, Earth Surface Processes and Landforms 35(10), pp. 1157-66.

Haff, P. K. (2012) Technology and human purpose: the problem of solids transport on the Earth's surface, Earth Syst. Dynam. 3(2), pp. 149-56.

Hall, C. A. S., Lambert, J. G. \& Balogh, S. B. (2014) EROI of different fuels and the implications for society, Energy Policy 64, pp. 141-52.

Hermann, W. A. (2006) Quantifying global exergy resources, Energy 31(12), pp. 1685-702.

Hidalgo, C. s. A. (2015) Why Information Grows: The Evolution of Order, from Atoms to Economies (London: Penguin Books).

Hoffmeyer, J. (1996) Signs of Meaning in the Universe (trans. B. J. Haveland; Bloomington, IN: Indiana University Press).

Ingold, T. (2000) The Perception of the Environment: Essays in Livelihood, Dwelling and Skill (London: Routledge).

Jonas, H. (2001) The Phenomenon of Life: Toward a Philosophical Biology (Evanston, IL: Northwestern University Press).

Kleidon, A. (2010) A basic introduction to the thermodynamics of the Earth system far from equilibrium and maximum entropy production, Philosophical Transactions of the Royal Society B: Biological Sciences 365(1545), pp. 1303-15.

Kok, J. F., Parteli, E. J. R., Michaels, T. I. \& Karam, D. B. (2012) The physics of wind-blown sand and dust, Reports on Progress in Physics 75(10), pp. 106901.

Law, J. (2006) Disaster in agriculture: or foot and mouth mobilities, Environment and Planning $A$ 38(2), pp. 227-39.

Leeder, M. (2011) Sedimentology and Sedimentary Basins: From Turbulence to Tectonics (Chichester: Wiley-Blackwell, 2nd edn).

Lenton, T. M. \& Watson, A. J. (2011) Revolutions that Made the Earth (Oxford: Oxford University Press).

Levinson, M. (2006) The Box: How the Shipping Container Made the World Smaller and the World Economy Bigger (Princeton: Princeton University Press). 
Lineweaver, C. H. \& Egan, C. A. (2008) Life, gravity and the second law of thermodynamics, Physics of Life Reviews 5(4), pp. 225-42.

Margulis, L. (1998) The Symbiotic Planet: A New Look at Evolution (London: Weidenfeld \& Nicolson).

Marks, F. D. (2003) Hurricanes, in: J. R. Holton, J. A. Curry \& J. A. Pyle (Eds.), Encyclopedia of Atmospheric Sciences (3; London: Elsevier Science), pp. 942-66.

Mazoyer, M. \& Roudart, L. (2006) A History of World Agriculture: From the Neolithic Age to the Current Crisis (trans. J. H. Membrez; London: Earthscan).

McMahon, T. A. \& Bonner, J. T. (1983) On Size and Life (New York: Scientific American Library: Distributed by W.H. Freeman).

Mohr, S. \& Khan, O. (2015) 3D printing and its disruptive impacts on supply chains of the future, Technology Innovation Management Review 5(11), pp. 20-5.

Monod, J. (1972) Chance and Necessity: An Essay on the Natural Philosophy of Modern Biology (London: William Collins Sons \& Co).

Mumford, L. (1934) Technics and Civilization (New York: Harcourt, Brace \& Company).

Nealson, K. H. (2011) Early sensibilities, in: L. Margulis, C. A. Asikainen \& W. E. Krumbein (Eds.), Chimeras and Consciousness: Evolution of the Sensory Self (Cambridge: MA: MIT Press), pp. 4552.

Odling-Smee, F. J., Laland, K. N. \& Feldman, M. W. (2003) Niche Construction: the Neglected Process in Evolution (Princeton: Princeton University Press).

Oyama, S., Griffiths, P. \& Gray, R. D. (eds.) (2001a) Cycles of Contingency: Developmental Systems and Evolution (Cambridge, MA: MIT Press).

Oyama, S., Griffiths, P. \& Gray, R. D. (2001b) Introduction: what Is developmental systems theory?, in: S. Oyama, P. Griffiths \& R. D. Gray (Eds.), Cycles of Contingency: Developmental Systems and Evolution (Cambridge, MA: MIT Press), pp. 1-11.

Pauly, D. \& Christensen, V. (1995) Primary production required to sustain global fisheries, Nature 374(6519), pp. 255-7.

Pawson, E. (2008) Plants, mobilities and landscapes: environmental histories of botanical exchange, Geography Compass 2(5), pp. 1464-77.

Piggott, S. (1992) Wagon, Chariot, and Carriage: Symbol and Status in the History of Transport (London: Thames and Hudson).

Pimpinelli, A. \& Villain, J. (1998) Physics of Crystal Growth (Cambridge: Cambridge University Press). Prigogine, I. \& Stengers, I. (1984) Order Out of Chaos: Man's New Dialogue with Nature (Toronto: Bantam Books).

Prockter, L. M. (2005) Ice in the solar system, Johns Hopkins APL Technical Digest 26(2), pp. 175-88.

Purcell, E. M. (1977) Life at low Reynolds number, American Journal of Physics 45(1), pp. 3-11.

Schaffartzik, A., Mayer, A., Gingrich, S., Eisenmenger, N., Loy, C. \& Krausmann, F. (2014) The global metabolic transition: regional patterns and trends of global material flows, 1950-2010, Global Environmental Change 26, pp. 87-97.

Schrödinger, E. (1944) What is Life? The Physical Aspect of the Living Cell (Cambridge: Cambridge University Press).

Serres, M. (2000) The Birth of Physics (Manchester: Clinamen Press).

Shiklomanov, I. A. (1993) World fresh water resources, in: P. H. Gleick (Ed.) Water in Crisis: A Guide to the World's Fresh Water Resources (New York: Oxford University Press), pp. 13-24.

Soter, S. (2006) What is a planet?, Astronomical Journal 132(6), pp. 2513-9.

Spitale, J. N., Jacobson, R. A., Porco, C. C. \& Owen Jr., W. M. (2006) The orbits of Saturn's small satellites derived from combined historic and Cassini imaging observations, The Astronomical Journal 132(2), pp. 692.

Stiegler, B. (1998) Technics and Time, 1: The Fault of Epimetheus (Stanford, CA: Stanford University Press).

Suomi, V. E., Limaye, S. S. \& Johnson, D. R. (1991) High winds of Neptune: a possible mechanism Science 251(4996), pp. 929-32. 
Szerszynski, B. (2016) Out of the Metazoic? Animals as a transitional form in planetary evolution, in: M. Tønnessen, S. Rattasepp \& K. Amstrong Oma (Eds.), Thinking about Animals in the Age of the Anthropocene (Lexington, MA: Lexington Books).

Szerszynski, B. (forthcoming) Viewing the technosphere in an interplanetary light, Anthropocene Review.

Tavares, P. (2013) The geological imperative: on the political ecology of the Amazonia's deep history, in: E. Turpin (Ed.) Architecture in the Anthropocene: Encounters Among Design, Deep Time, Science and Philosophy (Ann Arbor: Open Humanities Press), pp. 209-39.

Trueman, E. R. \& Jones, H. D. (1977) Crawling and burrowing, in: R. M. Alexander \& G. Goldspink (Eds.), Mechanics and Energetics of Animal Locomotion (London: Chapman and Hall), pp. 20421.

Tsing, A. L. (2005) Friction: An Ethnography of Global Connection (Princeton, NJ: Princeton University Press).

Urry, J. (2003) Global Complexity (Cambridge: Polity).

Vogel, S. (1994) Life in Moving Fluids: The Physical Biology of Flow (Princeton, NJ: Princeton University Press, 2nd edn).

Vogel, S. (2013) Comparative Biomechanics: Life's Physical World (Princeton: Princeton University Press, Second edition. edn).

Watson, A. J. (2008) Implications of an anthropic model of evolution for emergence of complex life and intelligence, Astrobiology 8(1), pp. 175-85.

Yafremava, L. S., Wielgos, M., Thomas, S., Nasir, A., Wang, M., Mittenthal, J. E. \& Caetano-Anolles, G. (2013) A general framework of persistence strategies for biological systems helps explain domains of life, Frontiers in Genetics 4.

Zalasiewicz, J., Williams, M. \& Waters, C. N. (2014) Can an Anthropocene Series be defined and recognized?, Geological Society, London, Special Publications 395.

Zhou, Y. \& Antonia, R. A. (1995) Memory effects in a turbulent plane wake, Experiments in Fluids 19(2), pp. 112-20. 